EPJ Web of Conferences 106, 04003 (2016)

DOI: $10.1051 /$ epjconf/201610604003

(C) Owned by the authors, published by EDP Sciences, 2016

\title{
2013 Review of Neutron and Non-Neutron Nuclear Data
}

\author{
N.E. Holden \\ Guest Physicist, National Nuclear Data Center, Brookhaven National Laboratory, Upton, NY 11973, \\ USA
}

\begin{abstract}
The results of a review and evaluation of neutron and non-neutron nuclear data published in the scientific literature over the past three years since the ISRD-14 Symposium has been performed and the highlights are presented. Included in the data review are the status of new chemical elements, new measurements of the isotopic composition for many chemical elements and the resulting change in the atomic weight values. New half-life measurements for both short-lived and long-lived nuclides, some alpha decay and double beta decay measurements for quasi-stable nuclides are discussed. The latest evaluation of atomic masses has been published. Data from new measurements on the very heavy (transmeitnerium) elements are discussed and tabulated. Data on various recent neutron cross section and resonance integral measurements are discussed and tabulated.
\end{abstract}

\section{Introduction}

The scientific literature is scanned and periodically reviewed for both neutron and non-neutron nuclear data. The data collected are evaluated and the resulting recommendations are published in the Handbook of Chemistry and Physics [1,2]. In this paper, the results of the review during the period 2010 through early 2014 are presented. The data on the 118 chemical elements with over three thousand radioactive nuclides, over seven hundred meta-stable states with half-lives that are greater than $1 \mu \mathrm{s}\left(10^{-6} \mathrm{~s}\right)$, as well as the known stable and quasi-stable nuclides with a terrestrial isotopic abundance have been reviewed. The status of the major data libraries is discussed. Significant data in a number of topical areas are presented and discussed.

\section{Periodic Table of the Chemical Elements}

The history of the process of discovery (synthesis) and the naming of chemical elements has been discussed previously [3]. The joint committee formed by IUPAC (International Union of Pure and Applied Chemistry) and IUPAP (International Union of Pure and Applied Physics) has the responsibility to review the claims of discovery of a new element and to investigate whether or not there has been an independent verification of each discovery. The claim of discovery of the elements with atomic (proton) number 114 and 116 has been approved and these elements are called flerovium with the chemical symbol, Fl, after the Russian physicist, Georgy Flerov, who discovered spontaneous fission in 1940 and livermorium with the chemical symbol, Lv, named after the location of the Lawrence Livermore National Laboratory in California, where some of the work was performed, respectively. These elements

This is an Open Access article distributed under the terms of the Creative Commons Attribution License 2.0, which permits unrestricted use, distribution, and reproduction in any medium, provided the original work is properly cited. 
Table 1. Revised Value and Uncertainty of Atomic Weights.

\begin{tabular}{|l|l|l|}
\hline Element & Revised Atomic Weight & Previous Atomic Weight \\
\hline Magnesium & {$[24.304,24.307]$} & $24.3050(6)$ \\
\hline Germanium & $72.630(2)$ & $72.630(8)$ \\
\hline Selenium & $78.971(8)$ & $78.96(3)$ \\
\hline Molybdenum & $95.95(1)$ & $95.96(2)$ \\
\hline Cadmium & $112.414(4)$ & $112.411(8)$ \\
\hline Indium & $114.818(1)$ & $114.818(3)$ \\
\hline Mercury & $200.592(3)$ & $200.59(2)$ \\
\hline Thorium & $232.0377(4)$ & $232.03806(2)$ \\
\hline
\end{tabular}

have been added to the Periodic Table [4]. Data on the synthesis of elements with $Z=115$ and 117 has been confirmed [5, 6]. Data on elements 113, 115, 117 and 118 are undergoing review by the joint committee.

With the release of the 2012 Atomic Mass Table [7], there have been minor changes to the atomic weight value or uncertainty for fifteen of the mono-nuclidic elements, beryllium, fluorine, aluminum, phosphorus, scandium, manganese, cobalt, arsenic, yttrium, niobium, cesium, praseodymium, holmium, thulium and gold. In addition, there have been changes to eight poly-nuclidic elements as shown in Table 1. The major change in the value for thorium is due to the recent determination that a significant and consistent amount of ${ }^{230} \mathrm{Th}$ at the level of approximately 200 parts-per-million in deep seawater has led to the recognition that thorium is not a mono-nuclidic element as previously thought. In rocks and minerals, only ${ }^{232} \mathrm{Th}$ occurs in significant amounts. The new result indicates that both ${ }^{230} \mathrm{Th}$ and ${ }^{232} \mathrm{Th}$ are shown to be present in terrestrial samples. In all of the tables presented, a value in parentheses refers to the uncertainty in the final digit(s) of the value presented. The revised value for magnesium, shown in brackets, indicates that the variation of the magnesium isotopic abundance ratios in nature exceed the uncertainty in the measurements of the magnesium isotopic abundance ratios in nature. The value is within the interval.

\section{Isotopic Composition of the Elements}

Changes in the isotopic composition of the elements could impact the evaluation of the response from neutron activation detectors used in reactor dosimetry. An irradiated detector usually has a normal composition of naturally occurring isotopes of an element. The measured reaction rate will depend on the natural abundance of the stable isotope undergoing the reaction in the foil.

New measurements of isotopic ratios performed on chemical elements often result in improved values of the isotope abundances. These new values of the isotope abundances are recommended for use both in determining the atomic weight values of the elements from their atomic masses and for use in fitting measured values of the neutron cross sections of the isotopes of an element with the measured value of the cross section for the natural element.

Immediately after the French discovery of the two billion year old natural nuclear chain reactor at the Oklo quarry in Gabon, Africa in 1972 [8], George Cowan at Los Alamos published results of a world wide search of samples of natural uranium ores attempting to find another example somewhere on earth of a natural nuclear reactor. Cowan's estimate for the ${ }^{238} \mathrm{U}^{235} \mathrm{U}$ ratio was 137.88 from all of his samples [9]. In recent years, there have been seventeen papers published in the literature with experimental results on natural uranium samples that have been calibrated against known standards. These experimental data results support an improved ${ }^{238} U /{ }^{235} U$ value of 137.8 (1) for the natural uranium isotope ratio and its uncertainty, which is now recommended.

The revised isotopic compositions for eight chemical elements [10] are presented in Table 2. 
Table 2. Revised Isotopic Abundances [10].

\begin{tabular}{|c|c|c|}
\hline Element & Nuclide & Isotopic Composition \\
\hline \multirow[t]{3}{*}{ Magnesium } & 24 & $0.78951(12)$ \\
\hline & 25 & $0.10020(8)$ \\
\hline & 26 & $0.11029(10)$ \\
\hline \multirow[t]{5}{*}{ Germanium } & 70 & $0.2052(19)$ \\
\hline & 72 & $0.2745(15)$ \\
\hline & 73 & $0.0776(8)$ \\
\hline & 74 & $0.3652(12)$ \\
\hline & 75 & $0.0775(12)$ \\
\hline \multirow[t]{6}{*}{ Selenium } & 74 & $0.0086(3)$ \\
\hline & 76 & $0.0923(7)$ \\
\hline & 77 & $0.0760(3)$ \\
\hline & 78 & $0.2369(2)$ \\
\hline & 80 & $0.4980(36)$ \\
\hline & 82 & $0.0882(15)$ \\
\hline \multirow[t]{7}{*}{ Molybdenum } & 92 & $0.14649(106)$ \\
\hline & 94 & $0.09187(33)$ \\
\hline & 95 & $0.15873(30)$ \\
\hline & 96 & $0.16673(8)$ \\
\hline & 97 & $0.09582(15)$ \\
\hline & 98 & $0.24292(80)$ \\
\hline & 100 & $0.09744(65)$ \\
\hline \multirow[t]{8}{*}{ Cadmium } & 106 & $0.01245(22)$ \\
\hline & 108 & $0.00888(11)$ \\
\hline & 110 & $0.12470(61)$ \\
\hline & 111 & $0.12795(38)$ \\
\hline & 112 & 0.24109 (12) \\
\hline & 113 & $0.12227(7)$ \\
\hline & 114 & $0.28754(81)$ \\
\hline & 116 & $0.07512(54)$ \\
\hline \multirow[t]{2}{*}{ Indium } & 113 & $0.04281(52$ \\
\hline & 115 & $0.95719(52)$ \\
\hline \multirow[t]{7}{*}{ Mercury } & 196 & $0.00155(12)$ \\
\hline & 198 & $0.10038(16)$ \\
\hline & 199 & $0.16938(39)$ \\
\hline & 200 & $0.23138(65)$ \\
\hline & 201 & $0.13170(66)$ \\
\hline & 202 & $0.29743(89)$ \\
\hline & 204 & $0.06818(35)$ \\
\hline \multirow[t]{2}{*}{ Thorium } & 230 & $0.0002(2)$ \\
\hline & 232 & $0.9998(2)$ \\
\hline
\end{tabular}

\section{Table of Atomic Masses}

The latest version of the Atomic Mass Table Evaluation has been published in December 2012 [7]. In addition, the NUBASE2012 evaluation of nuclear properties [11] has also been published. NUBASE2012 includes mass excess values, radioactive half-lives, decay modes and intensities, as well as the year of discovery of each nuclide.

\section{Radioactive Decay Constants}

The radioactive half-life of a nuclide (the reciprocal of the radioactive decay constant) is of interest to reactor dosimetry because the half-life of the product nucleus in a nuclear reaction has a direct impact on the determination of the reaction rates. 
Table 3. Latest measured half-live values of radioactive nuclides of interest.

\begin{tabular}{|l|l|l|}
\hline Nuclide & Half-Life (uncertainty) $\mathbf{s}=$ seconds; a =years & Method of Decay \\
\hline${ }^{1} \mathrm{n}$ & $610.5(5) \mathrm{s}$ & $\beta^{-}$decay \\
\hline${ }^{32} \mathrm{Si}$ & $172(2) \mathrm{a}$ & $\beta^{-}$decay \\
\hline${ }^{41} \mathrm{Ca}$ & $9.9(2) \times 10^{4} \mathrm{a}$ & Electron capture \\
\hline${ }^{50} \mathrm{~V}$ & $2.0(3) \times 10^{17} \mathrm{a}$ & Electron capture and $\beta^{-}$decay \\
\hline${ }^{63} \mathrm{Ni}$ & $99 .(3) \mathrm{a}$ & $\beta^{-}$decay \\
\hline${ }^{76} \mathrm{Ge}$ & $1.6(2) \times 10^{21} \mathrm{a}$ & $\beta^{-} \beta^{-}$decay \\
\hline${ }^{87} \mathrm{Rb}$ & $4.97(1) \times 10^{10} \mathrm{a}$ & $\beta^{-}$decay \\
\hline${ }^{94} \mathrm{Nb}$ & $2.04(4) \times 10^{4} \mathrm{a}$ & $\beta^{-}$decay \\
\hline${ }^{109} \mathrm{Cd}$ & $462.4(3) \mathrm{d}$ & Electron capture \\
\hline${ }^{136} \mathrm{Xe}$ & $2.3(2) \times 10^{21} \mathrm{a}$ & $\beta^{-} \beta^{-}$decay \\
\hline${ }^{146} \mathrm{Sm}$ & $68(7) \times 10^{6} \mathrm{a}$ & $\alpha$ decay \\
\hline${ }^{137} \mathrm{Cs}$ & $30.05(8) \mathrm{a}$ & $\beta^{-}$decay \\
\hline${ }^{184} \mathrm{Os}$ & $1.12(23) \times 10^{13} \mathrm{a}$ & $\alpha$ decay \\
\hline${ }^{209} \mathrm{Bi}$ & $1.99(7) \times 10^{19} \mathrm{a}$ & $\alpha$ decay \\
\hline
\end{tabular}

Half-lives and decay modes of nuclides were previously [12] presented. There have been a number of new measurements of the radioactive half-lives in the past few years. A latest revision [13] of these types of data is displayed in Table 3. Only nuclides whose data have changed since the last report are listed in the table.

Many nuclides previously shown in these tables have been considered to be stable nuclides, as long as their half-life value was larger than the age of the earth. A more recent definition of stability considers a nuclide as stable only if its radioactive decay has never been experimentally established. At the present time, among elements with a terrestrial isotopic abundance, there are only 245 stable nuclides, not the 287 stable nuclides often quoted in the literature. There are also 42 radioactive (quasi-stable) nuclides.

Many of these quasi-stable nuclides undergo the double beta decay $(\beta \beta)$ process, which involves the emission of two neutrinos. $(\beta \beta)$ modes without the emission of neutrinos $(0 v)$ have never been experimentally detected and are not listed in this table. The lower half-life limits of the $(0 v \beta \beta)$ decay mode nuclides are one or more orders of magnitude larger than $(2 v \beta \beta)$ decay mode nuclides.

\section{Data on the Very Heavy Chemical Elements}

For the very heavy elements (trans-meitnerium elements, $Z>109$ ), there are other modes of decay (determining factors in nuclide stability), such as spontaneous fission (sf) decay and cluster decay. Spontaneous fission decay is radioactive decay in which the nucleus breaks up into two approximately equal reaction products, both of which have very heavy masses (some fifteen to forty times larger than the alpha particle). Cluster decay is radioactive decay in which the emitted particle has a much smaller mass than that of a fission product but it is still a larger mass than the alpha particle (some three to eight times larger). For very heavy chemical elements, a path to the super-heavy elements is being explored. In the process of this investigation, new nuclides and elements are being discovered (synthesized). The present list [1] of the highest $Z$ elements $(Z>109)$ and their nuclides is shown in Table 4 . The $\alpha$ particle decay energy of ${ }^{285} \mathrm{Fl}$ has not been measured.

\section{Neutron Cross Sections}

Recent neutron cross section and resonance integral measurements [14] since a previous report [12] appear in Tables 5 and 6. Thermal cross sections and resonance integrals are expressed in units of barns (b) $=10^{-28} \mathrm{~m}^{2}$. The symbol, mb, refers to the unit milli-barns or $10^{-31} \mathrm{~m}^{2}$. The barn is a non-SI unit 
Table 4. Nuclear data of the very heavy chemical elements.

\begin{tabular}{|l|l|l|l|l|l|l|l|}
\hline Nuclide & Half Life & Decay Mode & aEnergy & Nuclide & Half Life & Decay Mode & aEnergy \\
\hline & & & $(\mathbf{M e V})$ & & & & $($ MeV $)$ \\
\hline${ }^{267} \mathrm{Ds}$ & $\sim 3 . \mu \mathrm{s}$ & $\alpha$ & 11.6 & ${ }^{284} \mathrm{Cn}$ & $\sim 0.10 \mathrm{~s}$ & $\mathrm{Sf}$ & ----- \\
\hline${ }^{269} \mathrm{Ds}$ & $0.17 \mathrm{~ms}$ & $\alpha$ & 11.11 & ${ }^{285} \mathrm{Cn}$ & $0.5(2) \mathrm{min}$ & $\alpha$ & 9.15 \\
\hline${ }^{270 \mathrm{~m}} \mathrm{Ds}$ & $\sim 6 . \mathrm{ms}$ & $\alpha$ & 10.95 & ${ }^{278} 113$ & $\sim 13 \mathrm{~s}$ & $\alpha$ & 9.6 \\
\hline${ }^{270 \mathrm{~g}} \mathrm{Ds}$ & $0.1 \mathrm{~ms}$ & $\alpha$ & 11.03 & ${ }^{282} 113$ & $4(1) \mathrm{s}$ & $\alpha$ & 9.74 \\
\hline${ }^{271 \mathrm{~m}} \mathrm{Ds}$ & $70 \mathrm{~ms}$ & $\alpha$ & 9.9 & ${ }^{283} 113$ & $\sim 0.48 \mathrm{~s}$ & $\alpha$ & 10.0 \\
\hline${ }^{271 \mathrm{~g}} \mathrm{Ds}$ & $1.6 \mathrm{~ms}$ & $\alpha$ & 10.8 & ${ }^{284} 113$ & $\sim 0.1 \mathrm{~s}$ & $\alpha$ & 10.1 \\
\hline${ }^{273 \mathrm{~m}} \mathrm{Ds}$ & $0.17 \mathrm{~ms}$ & $\alpha$ & 11.8 & ${ }^{285} 113$ & $\sim 0.07 \mathrm{~s}$ & $\alpha$ & 10.6 \\
\hline${ }^{273} \mathrm{Ds}$ & $11.8 \mathrm{~ms}$ & $\alpha$ & 9.73 & ${ }^{286} 113$ & $\sim 0.24 \mathrm{~ms}$ & $\alpha$ & 11.7 \\
\hline${ }^{277} \mathrm{Ds}$ & $6 . \mathrm{ms}$ & $\alpha$ & 10.6 & ${ }^{285} \mathrm{Fl}$ & $0.13 \mathrm{~s}$ & $\alpha$ & ot meas \\
\hline${ }^{279} \mathrm{Ds}$ & $0.18 \mathrm{~s}$ & $\alpha / 0.1, \mathrm{sf} / 0.9$ & $\sim 9.70$ & ${ }^{286} \mathrm{Fl}$ & $0.12 \mathrm{~s}$ & $\alpha / 0.5, \mathrm{sf} / 0.5$ & 10.2 \\
\hline${ }^{280} \mathrm{Ds}$ & $\sim 7.6 \mathrm{~s}$ & $\mathrm{Sf}$ & ----- & ${ }^{287} \mathrm{Fl}$ & $0.48 \mathrm{~s}$ & $\alpha$ & 10.0 \\
\hline${ }^{281} \mathrm{Ds}$ & $11 . \mathrm{s}$ & $\mathrm{Sf}$ & ----- & ${ }^{288} \mathrm{Fl}$ & $\sim 0.58 \mathrm{~s}$ & $\alpha /$ & 9.94 \\
\hline${ }^{282} \mathrm{Ds}$ & $0.5 \mathrm{~ms}$ & $\mathrm{Sf}$ & ----- & ${ }^{289} \mathrm{Fl}$ & $\sim 0.19 \mathrm{~s}$ & $\alpha$ & 9.82 \\
\hline${ }^{272} \mathrm{Rg}$ & $\sim 2 \mathrm{~ms}$ & $\alpha$ & 10.82 & ${ }^{287} 115$ & $\sim 0.03 \mathrm{~s}$ & $\alpha$ & 10.6 \\
\hline${ }^{274} \mathrm{Rg}$ & $\sim 6 \mathrm{~ms}$ & $\alpha$ & 11.2 & ${ }^{288} 115$ & $0.16(3) \mathrm{s}$ & $\alpha$ & 10.5 \\
\hline${ }^{278} \mathrm{Rg}$ & $\sim 4 \mathrm{~ms}$ & $\alpha$ & 10.7 & ${ }^{289} 115$ & $\sim 0.33 \mathrm{~s}$ & $\alpha$ & 10.3 \\
\hline${ }^{279} \mathrm{Rg}$ & $\sim 0.17 \mathrm{~s}$ & $\alpha$ & 10.4 & ${ }^{290} 115$ & $\sim 0.2 \mathrm{~s}$ & $\alpha$ & 9.95 \\
\hline${ }^{280} \mathrm{Rg}$ & $\sim 3.6 \mathrm{~s}$ & $\alpha$ & $\sim 9.74$ & ${ }^{290} \mathrm{Lv}$ & $7 \mathrm{~ms}$ & $\alpha$ & 10.8 \\
\hline${ }^{281} \mathrm{Rg}$ & $17(6) \mathrm{s}$ & $\mathrm{Sf}$ & ----- & ${ }^{291} \mathrm{Lv}$ & $0.02 \mathrm{~s}$ & $\alpha$ & $\sim 10.74$ \\
\hline${ }^{282} \mathrm{Rg}$ & $\sim 1 \mathrm{~min}$ & $\alpha$ & 9.0 & ${ }^{292} \mathrm{Lv}$ & $13(1) \mathrm{ms}$ & $\alpha$ & $\sim 10.66$ \\
\hline${ }^{277} \mathrm{Cn}$ & $\sim 0.7 \mathrm{~ms}$ & $\alpha$ & $11.5-11.7$ & ${ }^{293} \mathrm{Lv}$ & $0.06(5) \mathrm{s}$ & $\alpha$ & 10.5 \\
\hline${ }^{281} \mathrm{Cn}$ & $0.10 \mathrm{~s}$ & $\alpha$ & 9.15 & ${ }^{293} 117$ & $22(8) \mathrm{ms}$ & $\alpha$ & 11.0 \\
\hline${ }^{282} \mathrm{Cn}$ & $0.8 \mathrm{~ms}$ & $\mathrm{Sf}$ & ----- & ${ }^{294} 117$ & $\sim 0.05 \mathrm{~s}$ & $\alpha$ & 10.8 \\
\hline${ }^{283} \mathrm{Cn}$ & $4(1) \mathrm{s}$ & $\mathrm{sf} / 0.1, \alpha / 0.9$ & 9.52 & ${ }^{294} 118$ & $\sim 0.7 \mathrm{~ms}$ & $\alpha$ & 11.7 \\
\hline & & & & & & & \\
\hline
\end{tabular}

that is allowed by the SI [15]. Superscripts, $\mathrm{m}$ and $\mathrm{g}$, refer to meta-stable and ground state levels of the product nuclide. Subscript, f, refers to the neutron fission reaction. Subscript $\alpha$ refers to the (n, $\alpha$ ) reaction. Reactions without an $\mathrm{f}$ or $\alpha$ designation refer to neutron capture.

Papers presented at ND2012, the "International Conference on Nuclear Data for Science and Technology" were published in three separate volumes of the Nuclear Data Sheets journal, dated April, May and June 2014. The JEFF-3.2 evaluated neutron data library [16] was released on March 5, 2014 containing neutron data on 472 nuclides. Evaluation work, involved with the Collaborative International Evaluated Library Organization (CIELO) Project [17], deals with neutron reactions on ${ }^{1} \mathrm{H},{ }^{16} \mathrm{O},{ }^{56} \mathrm{Fe}$, ${ }^{235,238} \mathrm{U}$, and ${ }^{239} \mathrm{Pu}$. When the CIELO project is completed, the results will be incorporated into the next version of the ENDF/B-VII library. IRDFF-1.03, a new dosimetry cross section library with 91 reactions [18] was released on March 3, 2014 to supersede IRDFF-1.02 (2012) [19] and IRDF-2002 (2005) [20].

\section{General Topics in Nuclear Data}

The search for a high detector efficiency, helium-3/free, neutron detector has resulted in the development of a neutron detector based on Gas Electron Multiplier (GEM) technology tested at the ISIS spallation neutron source (UK) and TRIGA reactor at the Casaccia Research Center near Rome (Italy) using a series of borated glass layers placed in sequence along the neutron path [21]. Tests at ISIS reproduced the main features of the neutron spectrum compared to the standard neutron beam monitors used on the beam line. Monte Carlo simulations were performed to improve the final detector design in terms of achieving the best detector efficiency possible. 
Table 5. Latest measured values of thermal neutron cross sections.

\begin{tabular}{|l|c|l|c|}
\hline Nuclide & Thermal $\sigma$ (uncertainty) & Nuclide & Thermal $\sigma$ (uncertainty) \\
\hline${ }^{12} \mathrm{C}$ & $3.90(6) \mathrm{mb}$ & ${ }^{148} \mathrm{Nd}$ & $2.51(13) \mathrm{b}$ \\
\hline${ }^{23} \mathrm{Na}$ & $\sigma^{\mathrm{m}}=0.501(3) \mathrm{b}$ & ${ }^{147} \mathrm{Sm}$ & $\sigma_{\alpha}=0.3(3) \mathrm{mb}$ \\
\hline${ }^{23} \mathrm{Na}$ & $\sigma^{\mathrm{m}+\mathrm{g}}=0.542(3) \mathrm{b}$ & ${ }^{149} \mathrm{Sm}$ & $\sigma_{\alpha}=11.5(11) \mathrm{mb}$ \\
\hline${ }^{39} \mathrm{~K}$ & $2.28(4) \mathrm{b}$ & ${ }^{152} \mathrm{Gd}$ & $615(58) \mathrm{b}$ \\
\hline${ }^{40} \mathrm{~K}$ & $90(8) \mathrm{b}$ & ${ }^{155} \mathrm{Gd}$ & $56700(2100) \mathrm{b}$ \\
\hline${ }^{41} \mathrm{~K}$ & $1.62(3) \mathrm{b}$ & ${ }^{157} \mathrm{Gd}$ & $239000(6000) \mathrm{b}$ \\
\hline${ }^{64} \mathrm{Ni}$ & $1.59(2) \mathrm{mb}$ & ${ }^{158} \mathrm{Gd}$ & $2.15(14) \mathrm{b}$ \\
\hline${ }^{69} \mathrm{Ga}$ & $2.18(11) \mathrm{b}$ & ${ }^{165} \mathrm{Ho}$ & $\sigma^{\mathrm{g}}=59.7(25) \mathrm{b}$ \\
\hline${ }^{71} \mathrm{Ga}$ & $4.12(18) \mathrm{b}$ & ${ }^{165} \mathrm{Ho}$ & $\sigma^{\mathrm{g}}=58.6(18) \mathrm{b}$ \\
\hline${ }^{94} \mathrm{Zr}$ & $51.3(77) \mathrm{mb}$ & ${ }^{170} \mathrm{Er}$ & $7.80(35) \mathrm{b}$ \\
\hline${ }^{96} \mathrm{Zr}$ & $24.3(39) \mathrm{mb}$ & ${ }^{174} \mathrm{Yb}$ & $\sigma^{\mathrm{m}}=71.6(27) \mathrm{b}$ \\
\hline${ }^{133} \mathrm{Cs}$ & $\sigma^{\mathrm{m}}=2.77(14) \mathrm{b}$ & ${ }^{182} \mathrm{~W}$ & $20.5(14) \mathrm{b}$ \\
\hline${ }^{130} \mathrm{Ba}$ & $\sigma^{\mathrm{m}}=0.596(37) \mathrm{b}$ & ${ }^{183} \mathrm{~W}$ & $9.37(38) \mathrm{b}$ \\
\hline${ }^{130} \mathrm{Ba}$ & $\sigma^{\mathrm{g}}=7.15(34) \mathrm{b}$ & ${ }^{184} \mathrm{~W}$ & $1.43(10) \mathrm{b}$ \\
\hline${ }^{132} \mathrm{Ba}$ & $\sigma^{\mathrm{m}}=0.682(29) \mathrm{b}$ & ${ }^{186} \mathrm{~W}$ & $33.33(62) \mathrm{b}$ \\
\hline${ }^{132} \mathrm{Ba}$ & $\sigma^{\mathrm{g}}=7.51(32) \mathrm{b}$ & ${ }^{184} \mathrm{Os}$ & $3480(150) \mathrm{b}$ \\
\hline${ }^{134} \mathrm{Ba}$ & $\sigma^{\mathrm{m}}=33.4(24) \mathrm{mb}$ & ${ }^{189} \mathrm{Os}$ & $\sigma^{\mathrm{m}}=0.257(18) \mathrm{mb}$ \\
\hline${ }^{136} \mathrm{Ba}$ & $\sigma^{\mathrm{m}}=28.7(57) \mathrm{mb}$ & ${ }^{190} \mathrm{Os}$ & $\sigma^{\mathrm{m}}=9.03(49) \mathrm{b}$ \\
\hline${ }^{138} \mathrm{Ba}$ & $0.404(18) \mathrm{b}$ & ${ }^{190} \mathrm{Os}$ & $\sigma^{\mathrm{g}}=1.93(10) \mathrm{b}$ \\
\hline${ }^{136} \mathrm{Ce}$ & $\sigma^{\mathrm{m}}=0.344(16) \mathrm{b}$ & ${ }^{192} \mathrm{Os}$ & $3.19(16) \mathrm{b}$ \\
\hline${ }^{136} \mathrm{Ce}$ & $\sigma^{\mathrm{g}}=3.91(18) \mathrm{b}$ & ${ }^{206} \mathrm{~Pb}$ & $29(2) \mathrm{mb}$ \\
\hline${ }^{138} \mathrm{Ce}$ & $\sigma^{\mathrm{m}}=0.047(20) \mathrm{b}$ & ${ }^{207} \mathrm{~Pb}$ & $649(14) \mathrm{mb}$ \\
\hline${ }^{138} \mathrm{Ce}$ & $\sigma^{\mathrm{g}}=0.98(5) \mathrm{b}$ & ${ }^{237} \mathrm{~Np}$ & $170.4(7.4) \mathrm{b}$ \\
\hline${ }^{140} \mathrm{Ce}$ & $0.51(2) \mathrm{b}$ & ${ }^{242} \mathrm{Pu}$ & $19.6(39) \mathrm{b}$ \\
\hline${ }^{142} \mathrm{Ce}$ & $0.88(4) \mathrm{b}$ & ${ }^{243} \mathrm{Cm}$ & $\sigma_{\mathrm{f}}=667(26) \mathrm{b}$ \\
\hline
\end{tabular}

A recent experiment attempting to detect primordial ${ }^{244} \mathrm{Pu}$ on earth found only an upper limit of about an order of magnitude lower than a previous 1971 measurement [22].

The first observation of ground state di-neutron decay has been reported [23]. A collision between a neon beam and a beryllium target produced boron-17. This ${ }^{17} \mathrm{~B}$ beam was directed at another beryllium target, which produced ${ }^{16} \mathrm{Be}$ and a proton. ${ }^{16} \mathrm{Be}$ decays into ${ }^{14} \mathrm{Be}$ and two neutrons in about $10^{-21}$ seconds. The neutron pair was measured in the Modular Neutron Array. A neutron only nucleus had previously been considered physically impossible.

\section{Conclusion}

In the search for super-heavy elements, new elements are being synthesized (discovered) and are being verified, which leads to these new elements being added to the Periodic Table of Chemical Elements, where elements 114, flevorium, and 116, livermorium, are the latest examples. New data supporting the synthesis of elements 115 and 117 have been published. Newly measured isotope ratios have led to revised isotopic compositions, which could affect the fit between the isotopic and the elemental cross section and resonance integral values for some elements. The recent publication of the latest 2012 atomic mass table and the NUBASE2012 evaluation provides up to date information useful in theoretical calculations of nuclear structure and the probability of such processes as double beta decay. The latest versions of the JEFF-3.2 library [16] and the IRDFF library [18] were released in March 2014. Updates to the ENDF/B library are involved with the ongoing CIELO evaluation Project [17].

The concern about the unavailability of helium for neutron detectors has led to research to develop ${ }^{3} \mathrm{He} /$ free neutron detectors. Detectors using GEM technology have been tested. The latest research has 


\section{$15^{\text {th }}$ ISRD}

Table 6. Latest measured values of resonance integrals.

\begin{tabular}{|l|c|l|c|}
\hline Nuclide & Resonance integral (uncertainty) & Nuclide & Resonance integral (uncertainty) \\
\hline${ }^{41} \mathrm{~K}$ & $1.02(4) \mathrm{b}$ & ${ }^{142} \mathrm{Ce}$ & $1.25(6) \mathrm{b}$ \\
\hline${ }^{69} \mathrm{Ga}$ & $21.6(12) \mathrm{b}$ & ${ }^{148} \mathrm{Nd}$ & $14.6(13) \mathrm{b}$ \\
\hline${ }^{7 \mathrm{I}} \mathrm{Ga}$ & $29.5(15) \mathrm{b}$ & ${ }^{158} \mathrm{Gd}$ & $75.3(70) \mathrm{b}$ \\
\hline${ }^{13} \mathrm{Cs}$ & $\mathrm{RI}^{\mathrm{m}}=22.8(17) \mathrm{b}$ & ${ }^{15} \mathrm{Ho}$ & $\mathrm{RI}^{\mathrm{g}}=671(47) \mathrm{b}$ \\
\hline${ }^{130} \mathrm{Ba}$ & $\mathrm{RI}^{\mathrm{m}}=19.3(9) \mathrm{b}$ & ${ }^{165} \mathrm{Ho}$ & $\mathrm{RI}^{\mathrm{g}}=650(31) \mathrm{b}$ \\
\hline${ }^{130} \mathrm{Ba}$ & $\mathrm{RI}^{\mathrm{g}}=178(10) \mathrm{b}$ & ${ }^{170} \mathrm{Er}$ & $40.4(28) \mathrm{b}$ \\
\hline${ }^{132} \mathrm{Ba}$ & $\mathrm{RI}^{\mathrm{m}}=4.32(22) \mathrm{b}$ & ${ }^{184} \mathrm{Os}$ & $330(20) \mathrm{b}$ \\
\hline${ }^{132} \mathrm{Ba}$ & $\mathrm{RI}^{\mathrm{g}}=42.5(22) \mathrm{b}$ & ${ }^{189} \mathrm{Os}$ & $\mathrm{RI}^{\mathrm{m}}=32.9(19) \mathrm{mb}$ \\
\hline${ }^{134} \mathrm{Ba}$ & $\mathrm{RI}^{\mathrm{m}}=13.3(5) \mathrm{b}$ & ${ }^{190} \mathrm{Os}$ & $\mathrm{RI}^{\mathrm{m}}=25.4(15) \mathrm{b}$ \\
\hline${ }^{136} \mathrm{Ba}$ & $\mathrm{RI}^{\mathrm{m}}=3.49(17) \mathrm{b}$ & ${ }^{190} \mathrm{Os}$ & $\mathrm{RI}^{\mathrm{g}}=4.77(29) \mathrm{b}$ \\
\hline${ }^{138} \mathrm{Ba}$ & $0.382(20) \mathrm{b}$ & ${ }^{192} \mathrm{Os}$ & $7.45(45) \mathrm{b}$ \\
\hline${ }^{136} \mathrm{Ce}$ & $\mathrm{RI}^{\mathrm{m}}=5.5(3) \mathrm{b}$ & ${ }^{243} \mathrm{Am}$ & $\mathrm{RI}_{\mathrm{f}}=2.46(12) \mathrm{b}$ \\
\hline${ }^{136} \mathrm{Ce}$ & $\mathrm{RI}^{\mathrm{g}}=63.5(31) \mathrm{b}$ & ${ }^{244} \mathrm{Cm}$ & $\mathrm{RI}_{\mathrm{f}}=6.14(31) \mathrm{b}$ \\
\hline${ }^{138} \mathrm{Ce}$ & $\mathrm{RI}^{\mathrm{m}}=1.95(10) \mathrm{b}$ & ${ }^{246} \mathrm{Cm}$ & $\mathrm{RI}_{\mathrm{f}}=1.734(10) \mathrm{b}$ \\
\hline${ }^{138} \mathrm{Ce}$ & $\mathrm{RI}^{\mathrm{g}}=8.6(5) \mathrm{b}$ & ${ }^{247} \mathrm{Cm}$ & $\mathrm{RI}_{\mathrm{f}}=889(36) \mathrm{b}$ \\
\hline${ }^{140} \mathrm{Ce}$ & $0.55(2) \mathrm{b}$ & ${ }^{248} \mathrm{Cm}$ & $\mathrm{RI}_{\mathrm{f}}=3.61(20) \mathrm{b}$ \\
\hline
\end{tabular}

experimentally found a nucleus composed of only neutrons, which had previously been thought to be impossible. The previous existence of some primordial ${ }^{244} \mathrm{Pu}$ on earth has been brought into question by a recent experiment, which detected only an upper limit.

The amount of new and interesting data that is being generated every year is an very clear indication that the field of nuclear data remains very strong and extremely active.

This research was supported by the US-DOE under the contract DE-AC02-98CH10886. The assistance of J-P Hu (BNL) in the preparation of this paper and helpful discussions with J-P Hu and R N Reciniello (BNL, retired) are gratefully acknowledged.

\section{References}

[1] N. Holden, Table of Isotopes, Handbook of Chemistry \& Physics (95 ${ }^{\text {th }}$ Ed) W M Haynes, Boca Raton Fl. CRC Press Inc. (2014), Sec 11, pp 2-174 and updates

[2] N. Holden, Neutron Scattering \& Absorption Properties, Handbook of Chemistry \& Physics (95 ${ }^{\text {th }}$ Ed) W.M. Haynes, Boca Raton Fl. CRC Press Inc. (2014), Sec 11, pp 175-187 and updates

[3] N. Holden, Survey of Latest Evaluated Nuclear Data, J. ASTM Int., Vol. 3 (7) ID-JAI-13484 (2006), surf: http://www . astm.org

[4] R. Loss, J. Corish, Pure Applied Chemistry 84, 1669-1672 (2012)

[5] D. Rudolph, et al., Phys. Rev. Lett. 111, 112502 (2013)

[6] J. Khuyagbaatar, et al., Phys. Rev. Lett. 112, 172501 (2014)

[7] M. Wang, G. Audi, A. Wapstra, F. Kondev, M. MacCormick, X. Xu, B. Pfeiffer, Chinese Physics/C 36, 1603-2014 (2012)

[8] R. Bodu, H. Bouzigues, N. Morin, J. Pfiffelmann, CR Acad. Sci. Paris 275D, 1731 (1972)

[9] G. Cowan, H. Adler, Geochimica Cosmochimica Acta 40, 1487 (1976)

[10] Isotopic Composition of the Elements Report 2013 (IUPAC Technical Report) Pure Appl. Chem. 87 (2015) to be published

[11] G. Audi, et al., Chinese Physics/C 36, 1157-1286 (2012)

[12] N. Holden, 2010, review of Neutron and Non-neutron Nuclear data, J. ASTM Int. 9 (3) ID-JAI103989 (2012), surf: http: //www . astm.org 
[13] N. Holden, Table of Isotopes, Handbook of Chemistry \& Physics (96 ${ }^{\text {th }}$ Ed) W. Haynes, Boca Raton Fl. CRC Press Inc. (2015), to be published

[14] N. Holden, Neutron Scattering \& Absorption Properties, Handbook of Chemistry \& Physics (96 $6^{\text {th }}$ Ed) W. Haynes, Boca Raton Fl. CRC Press Inc. (2015), to be published

[15] Bureau International des Poids et Mesures, "The International System of Units (SI)", $8^{\text {th }}$ edition, Table 8, Other non-SI units, p. 127 (2006)

[16] JEFF-3.2, Evaluated Data Library-Neutron Data, March 5 (2014), surf: https://www. oecdnew.org/dbforms/data/eva/evatapes/jeff_32/

[17] The CIELO Collaboration: M Chadwick, et al., Nuclear Data Sheets 118, 1-25 (2014)

[18] Int. Reactor Dosimetry \& Fusion File, IRDFF v.1.03 (2014), surf: https://www.nds. iaea.org/IRDFF/

[19] R. Capote, et al., J. ASTM Int. (JAI) 9, (4) ID- JAI104119, 2012, surf: www . astm . org

[20] International Reactor Dosimetry File 2002 (IRDF-2002), IAEA Technical Reports Series No. 452, Vienna (2006), surf: http://www-nds.iaea.org/irdf-2002/docs/irdf-2002. pdf

[21] A. Pietropaolo, et al., Nuclear Instruments Methods A 729, 117-126 (2013)

[22] J. Lachner, et al., Phys. Rev. C 85, 015801 (2012)

[23] A. Spyrou, et al., Phys. Rev. Lett. 108, 102501 (2012) 